\title{
Validity of a portable spirometer in the communities of China
}

\author{
Shan Xiao ${ }^{1+}$, Fan Wu ${ }^{1+}$, Zihui Wang ${ }^{1 \dagger}$, Jianmin Chen ${ }^{2}$, Huajing Yang ${ }^{1}$, Youlan Zheng ${ }^{1}$, Zhishan Deng ${ }^{1}$, \\ Jieqi Peng ${ }^{1}$, Xiang Wen ${ }^{1}$, Peiyu Huang ${ }^{1}$, Cuiqiong Dai ${ }^{1}$, Lifei Lu ${ }^{1}$, Ningning Zhao ${ }^{1}$, Pixin Ran ${ }^{1 *}$ and Yumin Zhou ${ }^{1 *}$
}

\begin{abstract}
Background: The lack of simple and affordable spirometry has led to the missed and delayed diagnoses of chronic respiratory diseases in communities. The PUS201P is a portable spirometry developed to solve this problem.

Objective: We aimed to verify the consistency of the PUS201P spirometer with conventional Jaeger spirometer.

Methods: In this cross-sectional study, we randomly recruited 202 subjects aged $>40$ years. Testing with the portable spirometry and conventional spirometry were performed on all participants. We compared forced expiratory volume in one second (FEV $)$, forced vital capacity (FVC), FEV /FVC measured by the PUS201P device with the conventional spirometer. Pearson correlation coefficient and Interclass Correlation Coefficient (ICC) were assessed to confirm the consistency of the measures from two instruments. Bland-Altman graph was created to assess the agreement of the measures from two devices.

Results: 202 participants were included in this study. The ICC on FEV, FVC, FEV / FVC measured by the portable spirometer and the conventional spirometer were 0.95 (95\% confidence interval [Cl]: 0.94-0.96), 0.92 (95\% Cl: 0.900.94], 0.93 (95\% Cl: 0.91-0.95), respectively. The Bland-Altman plots showed that the mean difference between the measures from two spirometers are always located in the $95 \%$ limits of agreement.
\end{abstract}

Conclusions: Our results support that the measures from the portable spirometer and the conventional spirometer have a good agreement and reproducibility. And the portable spirometer is a reliable tool to screen and diagnose chronic airway diseases in the primary care settings.

Keywords: Portable spirometry, Chronic airway diseases, Consistency, Validity

\section{Background}

Spirometry is the fundament of respiratory function test and is the key to diagnosing and supervising the most common chronic respiratory diseases (CRD) [1], and is recommended in practice guidelines for

*Correspondence: pxran@gzhmu.edu.cn; zhouyumin410@163.com

†Shan Xiao, Fan Wu and Zihui Wang have contributed equally to this work

${ }^{1}$ National Center for Respiratory Medicine, State Key Laboratory

of Respiratory Disease, National Clinical Research Center for Respiratory

Disease, Guangzhou Institute of Respiratory Health, The First Affiliated

Hospital of Guangzhou Medical University, 151 Yanjiang Xi Road,

Guangzhou, China

Full list of author information is available at the end of the article the diagnosis and management of chronic obstructive pulmonary disease (COPD) and asthma [2,3]. What's more, as a diagnostic test, spirometry is a reliable, simple, non-invasive, safe, and non-expensive procedure for the detection of airflow obstruction [4]. Therefore, the spirometry as a currently available tool for the early diagnosis of COPD and asthma is particularly important. Epidemiological data show that CRD has contributed to the magnitude of the non-fatal health burden globally [5]. COPD is a worldwide public health challenge because of its high prevalence and related disability and mortality [6-9]. The Global Burden of Disease Study estimated that 3.2 million people has died from 
COPD worldwide in 2015 [7]. In China, COPD was the third leading cause of death and accounted for more than 0.9 million deaths in 2013 [10]. Asthma is also one of the most common CRD and the global prevalence of self-reported, doctor-diagnosed asthma in adults is 4.3\% (95\% confidence interval [CI]: 4.2-4.4) [11]. The United States healthcare system estimated that the total asthma related costs was continued to rise, and jumped from USD 53 billion for 2007 to USD 56 billion for 2009, and most recently USD 82 billion in 2013 [12, 13].

Considering the high prevalence and high mortality of CRD, it is important to promote spirometry. However, the respiratory function test is not widely used in the primary care settings. ERS (European Respiratory Society) guidelines quote evidence that up to $75 \%$ of COPD patients in Europe remain under-diagnosed [14]. And a large population-based survey reported that Chinese patients who have COPD, only $6.5 \%$ have been tested with spirometry [15]. A previous study noted that only $60 \%$ had been diagnosed with asthma, and less than $10 \%$ had objective assessment of airway function [16]. As a consequence of the lack of simple and affordable spirometry the missed diagnosis of CRD is common. Many CRD patients are usually diagnosed when their condition is very serious. CRD underdiagnosis delays the treatment opportunity. The Burden of Lung Disease estimates of COPD underdiagnosis are substantially higher than those reported for high blood pressure, hypercholesterolaemia, and other similar disorders [4]. Therefore, early diagnosis of CRD is a daunting task in primary care settings. This can be attributed to several factors, including heavy and expensive spirometry equipment, complex program, maintenance charge and professional training for the reliable quality of test and interpretation, influence the accessibility of conventional spirometry $[17,18]$. As a result, many primary care physicians require their patients to medical center for spirometric evaluation [19], and the financial burdens of patients were increased.

In recent years, quite a lot of portable spirometers have emerged on the market, only a part of the products has been accessed in clinical trials $[20,21]$. One of the portable spirometry used to detect pulmonary ventilation has a good consistency with the convention spirometer [22]. There are several kinds of spirometry, such as full body plethysmography, fully portable units that are wirelessly connected to mobile phones. One of the more popular methods for evaluating patients with CRD is a clinicalgrade, in-office, handheld spirometry solution [23]. At present, there are some evidences to support that handheld spirometer has good sensitivity and specificity to identify airflow limitation compared with standard laboratory-based spirometry [24-29].
One of the latest devices in China is marketed as PUS201P (Guangzhou Changhu Medical Equipment Co. LTD). The PUS201P is a handheld spirometer does not require regular calibration. It is a portable device connected to a smartphone or tablet computer via Bluetooth and verified by the medical device registration certificate of China. The smart spirometric indices included forced vital capacity (FVC), forced expiratory volume in $1 \mathrm{~s}\left(\mathrm{FEV}_{1}\right)$, forced expiratory volume in three seconds $\left(\mathrm{FEV}_{3}\right)$, forced expiratory volume in six seconds $\left(\mathrm{FEV}_{6}\right), \mathrm{FEV}_{1} / \mathrm{FVC}, \mathrm{FEV}_{3} / \mathrm{FVC}, \mathrm{FEV}_{6} / \mathrm{FVC}$, Peak expiratory flow (PEF), Maximum mid-expiratory flow (MMEF), forced expiratory flow after $25 \%$ of FVC has been exhaled (FEF25), forced expiratory flow after $50 \%$ of FVC has been exhaled (FEF50), forced expiratory flow after $75 \%$ of FVC has been exhaled (FEF75). The specific product appearance, work interface and quality control platform are shown in the Fig. 1.

The purpose of our research is to verify the consistency of the portable spirometer with traditional Jaeger spirometer, and whether the portable spirometer can be used in the screening and diagnosis of chronic airway diseases in primary care settings.

\section{Methods}

We conducted a cross-sectional study in Guangdong Province, China. We randomly recruited 202 subjects aged $>40$ years from June 2020 to October 2020. Patients who had any of the contraindications to make spirometry listed in the American Thoracic Society (ATS) and ERS guidelines were excluded: chest or abdominal pain of any cause, oral or facial pain exacerbated by a mouthpiece, stress incontinence, dementia or unconsciousness state [30]. We also excluded patients who did not provide informed consent and those who required more than 8 maneuvers in order to be able to meet reproducibility criteria.

Every participant was performed pulmonary function test with the conventional spirometer and the portable spirometer. The Jaeger spirometer needs linear verification, therefore, we did daily calibration with a $3 \mathrm{~L}$ syringe. The PUS201P does not need linear verification. The order of testing for the same patient was randomized and conducted in single-blind fashion, meaning the subjects were unaware as to which machine was under study [23]. Each patient was operated by the same physician-technician. Operations with both equipment were carried out by trained personnel in a standardized way, according to the ATS/ERS guidelines [31]. The acceptability criteria are a satisfactory start of test and a satisfactory end: 1) Start without hesitation, or back extrapolated volume $<5 \%$ of FVC or $0.150 \mathrm{~L}, 2$ ) without coughing during the first second of the operation, 3) without early termination of 

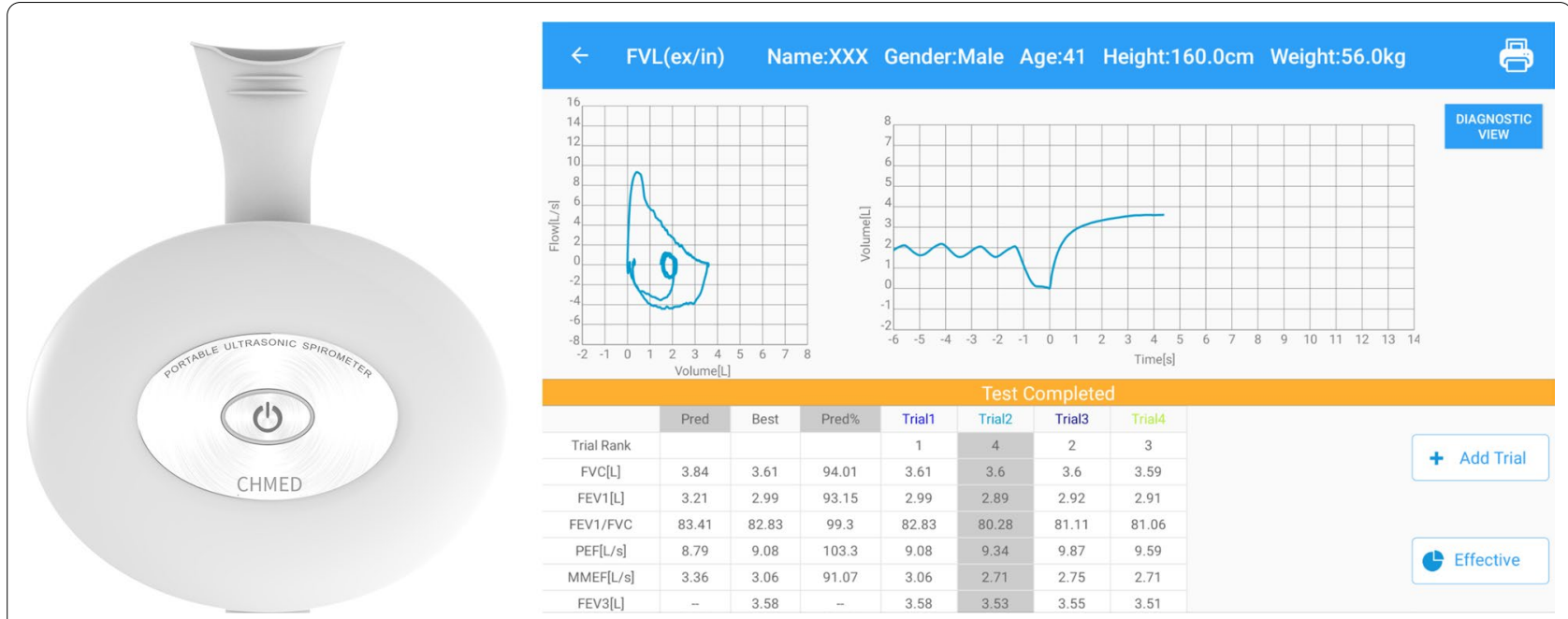

Fig. 1 The portable spirometer appearance, work interface and quality control platform. FVC forced vital capacity; FEV forced expiratory volume in one second; PEF peak expiratory flow; MMEF maximum mid-expiratory flow; $F E V_{3}$ forced expiratory volume in three seconds

expiration, 4) curve shows no change in volume for $1 \mathrm{~s}$ or exhalation times of $>6 \mathrm{~s}$ [31]. We did all spirometric manoeuvres with the participant in a seated position, wearing a nose clip, and using a disposable mouthpiece [32]. Every day we would store test results in the spirometer and downloaded them daily to a central computer system. An expert panel did quality control, excluded tests with poor quality [31]. For each spirometry were recorded the below parameters: $\mathrm{FVC}, \mathrm{FEV}_{1}, \mathrm{FEV}_{3}, \mathrm{FEV}_{6}$, $\mathrm{FEV}_{1} / \mathrm{FVC}, \mathrm{FEV}_{3} / \mathrm{FVC}, \mathrm{FEV}_{6} / \mathrm{FVC}$, PEF, FEF25, FEF50 and FEF75. Subjects with a pre-bronchodilator $\mathrm{FEV}_{1} /$ $\mathrm{FVC}<70 \%$ were defined as spirometry-defined COPD, and healthy control was defined as pre-bronchodilator $\mathrm{FEV}_{1} / \mathrm{FVC} \geq 70 \%$.

All subjects who had a successful spirometry test were required to complete a comprehensive questionnaire to collect data on age, sex, and smoking status. The questionnaire used in this study was a revised form of the international BOLD study [33]. The questionnaire covered demographic data, respiratory symptoms/disease, comorbidities, health care use, activity limitation, potential risk factors for COPD, and the modified Medical Research Council dyspnea scale (mMRC, scores range from 0 to 4 , with higher scores indicating more severe breathlessness), the changes in the COPD Assessment Test (CAT) score (scores range from 0 to 40, with higher scores indicating more severe disease score and health status). We defined current smoking as having smoked 100 cigarettes in one's lifetime and currently smoking cigarettes. We defined passive smoking as inhalation of smoke by nonsmokers who lived with smokers.

The participants were made fully aware of the purpose of study, and all subjects have signed the informed consent before the examination. The study was approved of The Ethics Commission of the First Affiliated Hospital of Guangzhou Medical University approved the study (No. 2018-53).

\section{Statistical analysis}

The qualitative variables were expressed by their absolute value and their percentage, and the quantitative variables are expressed as means and standard deviations (SD). The quality of a medical device was assessed by its consistency with the gold standard (i.e., conventional spirometry). The Bland-Altman method is the preferred method to assess agreement between medical instruments measuring continuous variables [34-36]. Therefore, BlandAltman method was used to describe the bias between the mean differences for the values obtained by the two devices with Medcalc software. The Pearson correlation coefficient and the Interclass Correlation Coefficient (ICC) were assessed to analyze the consistency of the two instruments. ICC and The Pearson correlation coefficient analyses were conducted using IBM SPSS statistics, version 25 . The scatter plot of correlation graphs obtained by the two spirometric devices with GraphPad Prism v. 8.0.2 (GraphPad Software, San Diego California, USA).

\section{Results}

A total of 202 subjects have randomly recruited from a cohort of people with chronic respiratory diseases in Guangdong Province, China. The baseline demographic characteristics of participants who completed questionnaires are showed in Table 1. The mean age of the volunteers was 58.2 years, and 98 (48.5\%) participants have never smoked, 78 (38.6\%) were current smoking, 26 
Table 1 Characteristics of the subjects

\begin{tabular}{ll}
\hline Characteristics & Patients (N= 202) \\
\hline Age- year & $58.24 \pm 9.72$ \\
Sex-no. (\%) & $133(65.84)$ \\
$\quad$ Male sex & $69(34.16)$ \\
$\quad$ Female sex & $23.47 \pm 3.26$ \\
Body-mass index & \\
Smoking status & $98(48.52)$ \\
$\quad$ Never smoked & $78(38.61)$ \\
$\quad$ Current smoking & $26(12.87)$ \\
$\quad$ Former smoking & \\
mMRC dyspnea scale score & \\
Distribution-no. (\%) & $198(98.02)$ \\
$\quad<2$ & $4(1.98)$ \\
$\geq 2$ & \\
CAT score & \\
Distribution-no. (\%) & \\
$\quad<10$ & $188(93.01)$ \\
$\geq 10$ & $14(6.99)$ \\
Spirometry-defined COPD & $55(27.2)$ \\
\hline
\end{tabular}

mMRC modified Medical Research Council; CAT COPD Assessment Test; COPD chronic obstructive pulmonary disease

(12.9\%) were former smoking. 198 (98.0\%) people had a mMRC score $<2,14$ of 202 subjects have got a CAT score of 10 or more.

In this study, spirometry was performed on every participant with the conventional spirometer and the simple spirometer. For the sake of obtain representative results, the order of testing was randomized. The following spirometric parameters were recorded for all participants from two spirometers: FVC, $\mathrm{FEV}_{1}, \mathrm{FEV}_{1} / \mathrm{FVC}$, PEF, MMEF, FEF25, FEF50 and FEF75. The key spirometric parameters of 202 patients measured with two spirometers were showed in Table 2.

We adapted Pearson correlation coefficients and ICC to evaluate the concordance and correlation between the two devices. Table 3 showed that the metrics (Pearson correlation and ICC) of all parameters have significant $(p<0.001)$. The metrics of several key parameters $\left(\mathrm{FEV}_{1}\right.$, $\mathrm{FVC}, \mathrm{FEV}_{1} / \mathrm{FVC}$ ) were greater than 0.92. All parameters had great concordance and correlation between the two spirometers in spirometry-defined COPD or healthy control subjects (Additional file 1: Table S1 and Table S2).
Table 2 Key spirometric parameters of 202 patients, with both spirometers: (1) Jaeger spirometer and (2) PUS201P spirometer

\begin{tabular}{llccc}
\hline Parameters & Group & Mean & SD & Max-Min \\
\hline FVC, L & Jaeger & 3.21 & 0.70 & $4.86-1.50$ \\
& PUS201P & 3.13 & 0.67 & $4.76-1.56$ \\
FEV $_{1}, \mathrm{~L}$ & Jaeger & 2.36 & 0.63 & $3.81-0.73$ \\
& PUS201P & 2.31 & 0.61 & $3.97-0.73$ \\
FEV $_{1}$ /FVC, \% & Jaeger & 73.55 & 10.85 & $92.79-31.85$ \\
& PUS201P & 73.44 & 10.34 & $92.55-32.52$ \\
MMEF, L/s & Jaeger & 1.85 & 0.99 & $6.34-0.19$ \\
& PUS201P & 1.96 & 0.96 & $5.84-0.22$ \\
PEF, L/s & Jaeger & 6.00 & 1.88 & $11.21-2.09$ \\
& PUS201P & 5.82 & 1.88 & $11.51-1.96$ \\
FEF25, L/s & Jaeger & 5.10 & 1.95 & $10.14-0.58$ \\
& PUS201P & 5.00 & 1.91 & $9.79-0.60$ \\
FEF50, L/s & Jaeger & 2.56 & 1.28 & $7.33-0.25$ \\
& PUS201P & 2.63 & 1.25 & $7.63-0.22$ \\
FEF75, L/s & Jaeger & 0.61 & 0.41 & $2.88-0.07$ \\
& PUS201P & 0.69 & 0.40 & $2.69-0.08$ \\
\hline
\end{tabular}

FEV ${ }_{1}$ forced expiratory volume in one second; FVC forced vital capacity; MMEF maximum mid-expiratory flow; PEF peak expiratory flow; FEF 25 forced expiratory flow after $25 \%$ of FVC has been exhaled; FEF50 forced expiratory flow after $50 \%$ of FVC has been exhaled; FEF75 forced expiratory flow after $75 \%$ of FVC has been exhaled

Table 3 Pearson correlation coefficients and intraclass correlation coefficients (ICC) between the spirometric values obtained with the two spirometers, for the entire dataset (202 patients)

\begin{tabular}{lllll}
\hline & $\begin{array}{l}\text { Pearson } \\
\text { correlation }\end{array}$ & $\boldsymbol{p}$ value & ICC (95\%Cl) & $p$ value \\
\hline $\mathrm{FEV}_{1}, \mathrm{~L}$ & 0.951 & $<0.001$ & $0.951(0.935-0.962)$ & $<0.001$ \\
$\mathrm{FVC}, \mathrm{L}$ & 0.925 & $<0.001$ & $0.924(0.901-0.942)$ & $<0.001$ \\
$\mathrm{FEV}_{1} / \mathrm{FVC}, \%$ & 0.934 & $<0.001$ & $0.933(0.913-0.949)$ & $<0.001$ \\
$\mathrm{MMEF}^{\mathrm{L}} \mathrm{L} / \mathrm{s}$ & 0.864 & $<0.001$ & $0.863(0.824-0.895)$ & $<0.001$ \\
$\mathrm{PEF}_{1} \mathrm{~L} / \mathrm{s}$ & 0.872 & $<0.001$ & $0.875(0.838-0.904)$ & $<0.001$ \\
$\mathrm{FEF}_{25}, \mathrm{~L} / \mathrm{s}$ & 0.913 & $<0.001$ & $0.913(0.887-0.933)$ & $<0.001$ \\
$\mathrm{FEF}_{50}, \mathrm{~L} / \mathrm{s}$ & 0.888 & $<0.001$ & $0.888(0.855-0.914)$ & $<0.001$ \\
$\mathrm{FEF}_{75}, \mathrm{~L} / \mathrm{s}$ & 0.774 & $<0.001$ & $0.774(0.712-0.824)$ & $<0.001$
\end{tabular}

CI Confidence interval; $F E V_{1}$ forced expiratory volume in one second; FVC forced vital capacity; MMEF maximum mid-expiratory flow; PEF peak expiratory flow; FEF25 forced expiratory flow after $25 \%$ of FVC has been exhaled; FEF50 forced expiratory flow after $50 \%$ of FVC has been exhaled; FEF75 forced expiratory flow after $75 \%$ of FVC has been exhaled

(See figure on next page.)

Fig. 2 Correlation plots between the values obtained from the two spirometers, for the spirometric parameters considered in this research. FEV ${ }_{1}$ forced expiratory volume in one second; FVC forced vital capacity; MMEF maximum mid-expiratory flow; PEF peak expiratory flow; FEF25 forced expiratory flow after $25 \%$ of FVC has been exhaled; FEF50 forced expiratory flow after $50 \%$ of FVC has been exhaled; FEF75 forced expiratory flow after $75 \%$ of FVC has been exhaled. Note ${ }^{*}=$ measured by the portable spirometer; ${ }^{* *}=$ measured by the conventional spirometer 

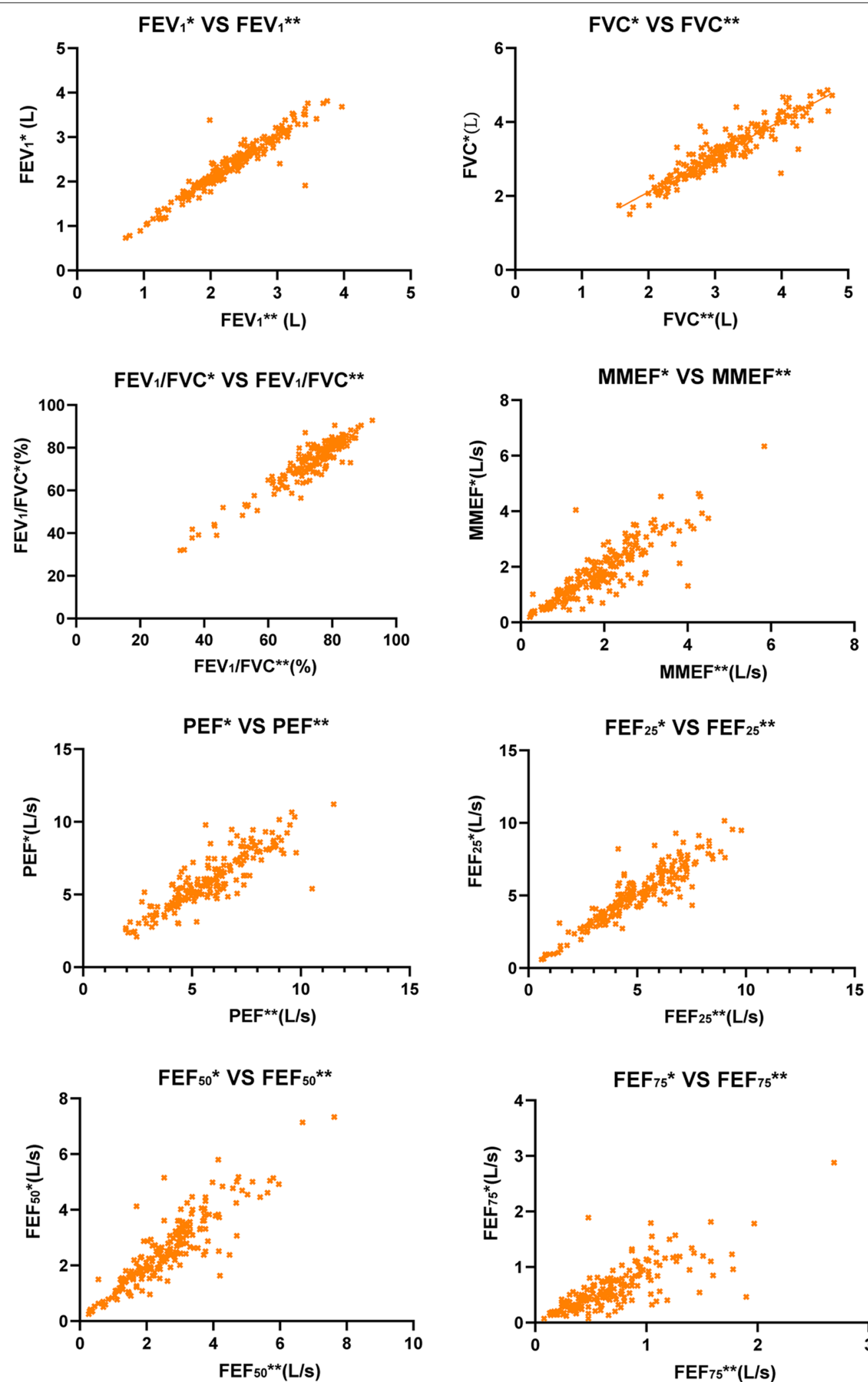

Fig. 2 (See legend on previous page.)

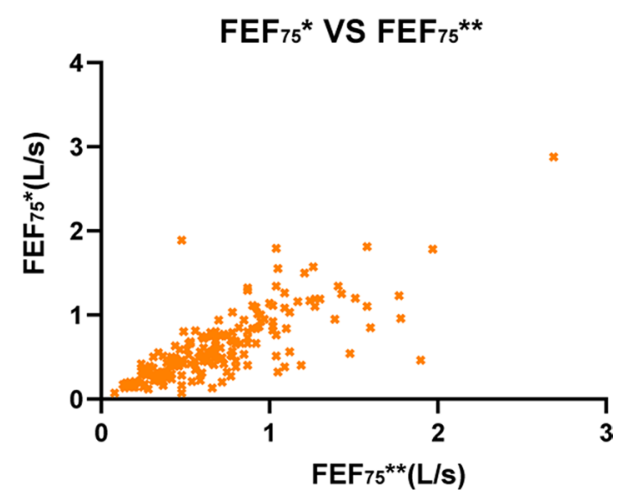


A strong linear relationship was found between two devices in all parameters (Fig. 2). As exhibited in the plots, there was significant agreement between the two spirometers. The correlation of $\mathrm{FEV}_{1}$ between the portable spirometer and Jaeger spirometer was the strongest $(r=0.904, p<0.001)$, while the correlation of MMFE, PEF, FEF75 was slightly weak.

The Bland-Altman plot was drawn to display the mean difference or bias and $95 \%$ limits of agreement (95\%LoA, $\pm 1.96 \mathrm{SD})$ between devices for each value measured (Fig. 3). In these plots, we can find that most of the mean difference were located in the 95\%LoA. It can be supported that the results of the two devices have a good consistent.

\section{Discussion}

Aimed to assess whether results from spirometry with the portable spirometer is reliable. The results of our study indicated that the validity and quality of spirometric indices by the portable spirometer is satisfactory in comparison with the conventional spirometer (Jaeger spirometer). Spirometric measurements with the portable spirometer presented great agreement (calculated by Pearson correlation coefficients and ICC) and reproducibility (in the Bland-Altman plots) with the Jaeger spirometer. Great ICC values were obtained for all measured variables consistently.

The ICC and Pearson correlation coefficients values between two devices parameters reflected great reliability. The metrics of certain key parameters $\left(\mathrm{FEV}_{1}, \mathrm{FVC}, \mathrm{FEV}_{1}\right.$ / FVC) were greater than 0.92. Although ICC values of MMEF, PEF, FEF75 were slightly lower but remained significant $(>0.75)$, which was in line with previous findings [25, 37-39]. The participants did not exert continuous force to reach the flow limit during the whole process of FVC measurement may affect this result.

Spirometry is recommended as a diagnostic and therapeutic tool in primary care setting, and it should be promoted as a method of facilitating accurate diagnosis of chronic obstructive pulmonary disease [40]. Unfortunately, spirometry is invaluable as a screening test of general respiratory health in the same way that blood pressure provides important information about general cardiovascular health [31]. There's an evidence showed spirometry remains largely underused in primary care [17]. This may be attributable to several factors, including large disparities in health care resources, negligence of primary care physicians and the patient [23]. So, it is important to apply a new medical device that is cheap, easy to operate, and as accurate as the gold standard method.

At present, there are several portable spirometers validated to date, such as the Air Next spirometer and the EasyOne spirometer [41, 42]. For example, the Air Next spirometer is the disposable turbines a pre-calibrated tachograph and does not need calibration [41]. Our portable spirometer is a handheld spirometer equipped with an ultrasonic sensor to measure air flow, and the accuracy of this portable spirometer is not influenced by daily temperature and humidity. Our portable spirometer has a great application prospect. It has high consistency with conventional spirometer, lower instrument cost, smaller size for easy handling, less effort to perform the test, improved ease of calibration checks.

This is the first study to assess the validity and safety of the portable spirometer device with conventional spirometer in Chinese community. All participants were recruited from community screening. And there were many healthy subjects, not only the patients included in our study, which were different from previous study [22, 23, 41]. Our research focused on the potential application of the portable pulmonary function instrument in the communities. From a methodological point of view, randomization of the order for the conventional spirometer and the portable spirometer is important to come out with a reliable result [43]. Another crucial concern on the utilization of portable spirometers is the cost of instruments. Our smart spirometer is much cheaper than traditional spirometer.

There are several limitations in our study. First, the study was designed to determine the agreement and validity of a portable spirometer, thus the bronchodilator reversibility testing was not routinely performed as part of our procedure. Second, the measurement of Jaeger pulmonary function instrument is regarded as the "standard" artificially, however, there are also systematic errors in the conventional spirometry. In addition to, our portable spirometry can only detect pulmonary ventilation function, but not diffusion function and impulse oscillometry. Although the limitations of portable spirometry were significant, spirometry in confirming and excluding obstructive airway disease is essential for early diagnosis and treatment of CRD in the primary care [44].

\footnotetext{
(See figure on next page.)

Fig. 3 Bland-Altman plots for the evaluated spirometric parameters: FEV 1 , FVC, FEV 1 /FVC, MMEF, PEF, FEF25, FEF50, FEF75. Dashed lines represent the mean difference between measurements and dotted lines the $95 \%$ limits of agreement. FEV forced expiratory volume in one second; $F V C$ forced vital capacity; MMEF maximum mid-expiratory flow; PEF peak expiratory flow; FEF25 forced expiratory flow after $25 \%$ of FVC has been exhaled; FEF50 forced expiratory flow after $50 \%$ of FVC has been exhaled; FEF75 forced expiratory flow after $75 \%$ of FVC has been exhaled. Note ${ }^{*}=$ measured by the portable spirometer; ${ }^{* *}=$ measured by the conventional spirometer
} 

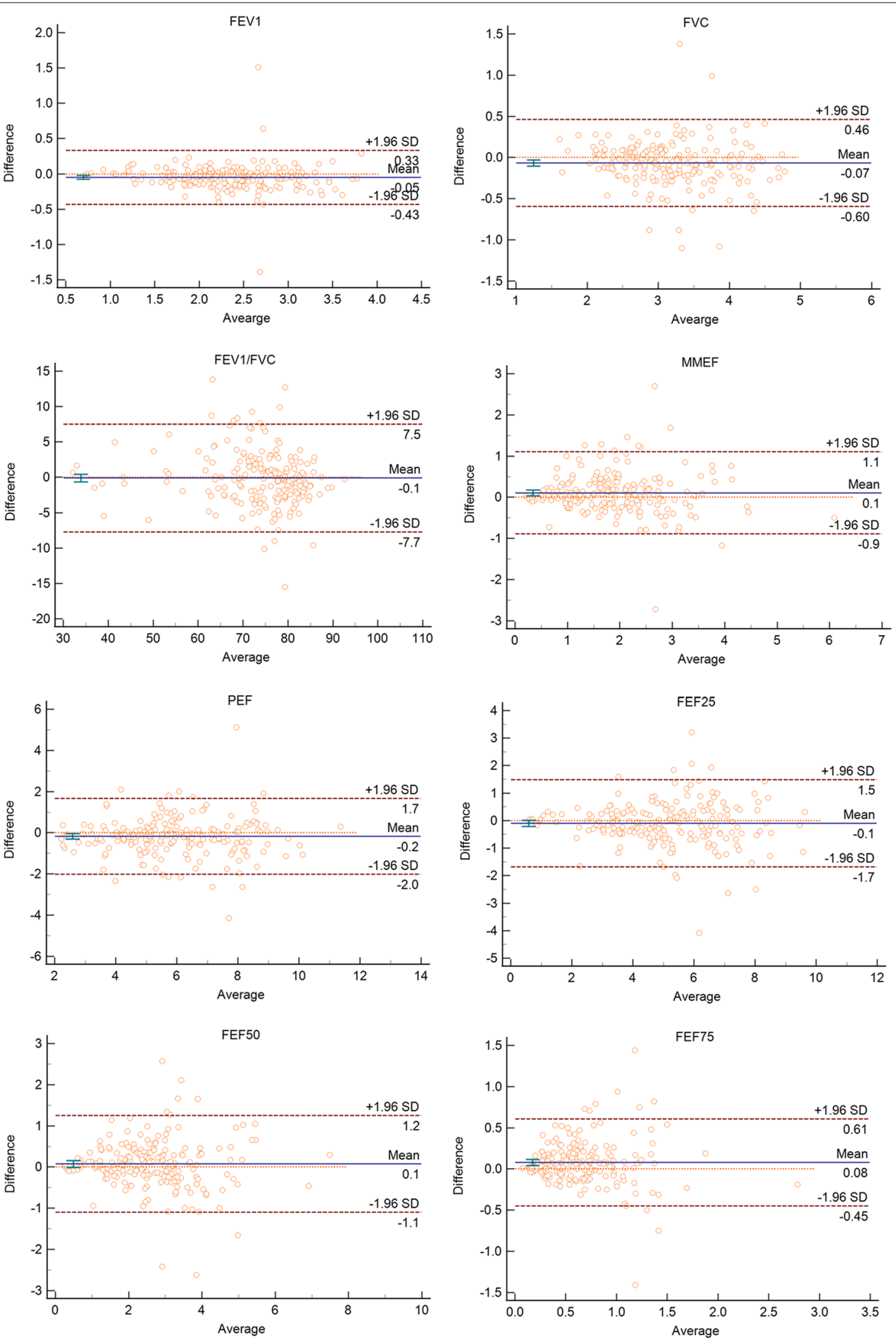

Fig. 3 (See legend on previous page.) 


\section{Conclusion}

Our findings suggested that spirometric measurements with the PUS201P spirometer has a good agreement and reproducibility with the Jaeger spirometer. And the PUS201P is a reliable tool to screen and diagnosis chronic respiratory diseases in primary care setting.

\section{Abbreviations}

$\mathrm{Cl}$ : Confidence interval; CRD: Chronic respiratory disease; COPD: Chronic obstructive pulmonary disease; $\mathrm{FEV}_{1}$ : Forced expiratory volume in one second; $\mathrm{FEV}_{3}$ : Forced expiratory volume in three seconds; $\mathrm{FEV}_{6}$ : Forced expiratory volume in six seconds; FVC: Forced vital capacity; MMEF: Maximum midexpiratory flow; L/s: Litres per second; PEF: Peak expiratory flow; FEF25: Forced expiratory flow after $25 \%$ of FVC has been exhaled; FEF50: Forced expiratory flow after $50 \%$ of FVC has been exhaled; FEF75: Forced expiratory flow after $75 \%$ of FVC has been exhaled; CAT: COPD assessment test; mMRC: modified Medical Research Council; ATS: American Thoracic Society; ERS: European Respiratory Society.

\section{Supplementary Information}

The online version contains supplementary material available at https://doi. org/10.1186/s12890-022-01872-9.

Additional file 1. Table S1. COPD group's Pearson correlation coefficients between the spirometric values obtained with the two spirometers, for the entire dataset (55 patients). Table S2. Health group's Pearson correlation coefficients between the spirometric values obtained with the two spirometers, for the entire dataset (147 patients).

\section{Acknowledgements}

We thank Shaodan Wei, Xiaopeng Ling, Wenjun Lai, and Qiaoyi He (National Center for Respiratory Medicine, State Key Laboratory of Respiratory Disease, National Clinical Research Center for Respiratory Disease, Guangzhou Institute of Respiratory Health, The First Affiliated Hospital of Guangzhou Medical University, Nanshan Medicine Innovation Institute of Guangdong Province), for their efforts in collecting the information and verification.

\section{Authors' contributions}

$Y Z$ and PR designed the study. SX, FW and ZW participated in data organization. SX, FW and ZW participated in data analysis. YZ, PR, SX, FW and ZW contributed to interpretation of the findings. SX, FW and ZW drafted the manuscript. YZ and PR contributed to article modification. Other authors participated in data collection. All authors have contributed to the last version of the manuscript. All authors read and approved the final manuscript.

\section{Funding}

This work was supported by the 13th five-year National Key Research and Development Program of China (2016YFC1304101), the National Science Foundation of China (81970045), Local Innovation and Research Team Project of Guangdong Pearl River Talents Program (2017BT01S155), Zhongnanshan Medical Foundation of Guangdong Province (ZNSA-2020003, ZNSA-2020012 and ZNSA-202113), the independent project of the State Key Laboratory of Respiratory Diseases (SKLRD-QN-201913). Study funding had no influence on the study.

\section{Availability of data and materials}

The datasets used and/or analyzed during the current study are available from the corresponding author on reasonable request.

\section{Declarations}

\section{Ethical approval and consent to participate}

The study was approved by the Ethics Commission of the First Affiliated Hospital of Guangzhou Medical University (No. 2018-53). The participants were made fully aware of the purpose of study, and all subjects have signed the informed consent before the examination. All methods were carried out in accordance with relevant guidelines and regulations. Informed consent was obtained from all subjects.

\section{Consent for publication}

Not applicable.

\section{Competing interests}

All of the authors declare no competing interests.

\section{Author details}

${ }^{1}$ National Center for Respiratory Medicine, State Key Laboratory of Respiratory Disease, National Clinical Research Center for Respiratory Disease, Guangzhou Institute of Respiratory Health, The First Affiliated Hospital of Guangzhou Medical University, 151 Yanjiang Xi Road, Guangzhou, China. ${ }^{2}$ Guangzhou Changhu Medical Devices Co, Ltd., Guangzhou, China.

Received: 5 October 2021 Accepted: 28 February 2022

Published online: 05 March 2022

\section{References}

1. Wheatley JR. Spirometry: key to the diagnosis of respiratory disorders. Med J Aust. 2017;207(10):422-3.

2. Pauwels RA, Buist AS, Calverley PM, Jenkins CR, Hurd SS. Global strategy for the diagnosis, management, and prevention of chronic obstructive pulmonary disease. NHLBI/WHO Global Initiative for Chronic Obstructive Lung Disease (GOLD) Workshop summary. Am J Respir Crit Care Med. 2001;163(5):1256-76.

3. Celli BR. The importance of spirometry in COPD and asthma: effect on approach to management. Chest. 2000;117(2 Suppl):15s-s19.

4. Soriano JB, Zielinski J, Price D. Screening for and early detection of chronic obstructive pulmonary disease. Lancet. 2009:374(9691):721-32.

5. GBD 2017 Disease and Injury Incidence and Prevalence Collaborators. Global, regional, and national incidence, prevalence, and years lived with disability for 354 diseases and injuries for 195 countries and territories, 1990-2017: a systematic analysis for the Global Burden of Disease Study 2017. Lancet. 2018;392(10159):1789-858.

6. GBD 2015 Disease and Injury Incidence and Prevalence Collaborators. Global, regional, and national incidence, prevalence, and years lived with disability for 310 diseases and injuries, 1990-2015: a systematic analysis for the Global Burden of Disease Study 2015. Lancet. 2016;388(10053):1545-602.

7. GBD 2015 Chronic Respiratory Disease Collaborators. Global, regional, and national deaths, prevalence, disability-adjusted life years, and years lived with disability for chronic obstructive pulmonary disease and asthma, 1990-2015: a systematic analysis for the Global Burden of Disease Study 2015. Lancet Respir Med. 2017:5(9):691-706.

8. Adeloye D, Chua S, Lee C, Basquill C, Papana A, Theodoratou E, et al. Global and regional estimates of COPD prevalence: systematic review and metaanalysis. J Glob Health. 2015;5(2):020415.

9. GBD 2015 Mortality and Causes of Death Collaborators. Global, regional, and national life expectancy, all-cause mortality, and cause-specific mortality for 249 causes of death, 1980-2015: a systematic analysis for the Global Burden of Disease Study 2015. Lancet. 2016:388(10053):1459-544.

10. Zhou M, Wang H, Zhu J, Chen W, Wang L, Liu S, et al. Cause-specific mortality for 240 causes in China during 1990-2013: a systematic subnational analysis for the Global Burden of Disease Study 2013. Lancet. 2016;387(10015):251-72

11. Papi A, Brightling C, Pedersen S, Reddel HJL. Asthma. Lancet. 2018;391(10122):783-800.

12. Nunes C, Pereira AM, Morais-Almeida M. Asthma costs and social impact. Asthma Res Pract. 2017;3:1

13. Nurmagambetov T, Kuwahara R, Garbe P. The Economic Burden of Asthma in the United States, 2008-2013. Ann Am Thorac Soc. 2018;15(3):348-56.

14. Rudolf M. The reality of drug use in COPD: the European perspective. Chest. 2000;117(2 Suppl):29s-32s. 
15. Zhong N, Wang C, Yao W, Chen P, Kang J, Huang S, et al. Prevalence of chronic obstructive pulmonary disease in China: a large, population-based survey. Am J Respir Crit Care Med. 2007;176(8):753-60.

16. Becker AB, Abrams EM. Asthma guidelines: the Global Initiative for Asthma in relation to national guidelines. Curr Opin Allergy Clin Immunol. 2017;17(2):99-103.

17. Heffler E, Crimi C, et al. Misdiagnosis of asthma and COPD and underuse of spirometry in primary care unselected patients. Respir Med. 2018;142:48-52.

18. Caramori G, Bettoncelli G, Tosatto R, Arpinelli F, Visonà G, Invernizzi G, et al. Underuse of spirometry by general practitioners for the diagnosis of COPD in Italy. Monaldi Arch Chest Dis. 2005;63(1):6-12.

19. Blain EA, Craig TJ. The use of spirometry in a primary care setting. Int J Gen Med. 2009;2009(2):183-6.

20. Represas-Represas C, Fernández-Villar A, Ruano-Raviña A, Priegue-Carrera A, Botana-Rial M. Screening for chronic obstructive pulmonary disease: validity and reliability of a portable device in non-specialized healthcare settings. PLOS ONE. 2016;11(1):e0145571.

21. Barr RG, Stemple KJ, Mesia-Vela S, Basner RC, Derk SJ, Henneberger PK, et al. Reproducibility and validity of a handheld spirometer. Respir care. 2008:53(4):433-41.

22. Ramos Hernández C, Núñez Fernández M, Pallares Sanmartín A, Mouronte Roibas C, Cerdeira Domínguez L, Botana Rial MI et al. Validation of the portable Air-Smart Spirometer. PLoS ONE. 2018;13(2):e0192789.

23. Chen G, Jiang L, Wang L, Zhang W, Castillo C, Fang X. The accuracy of a handheld "disposable pneumotachograph device" in the spirometric diagnosis of airway obstruction in a Chinese population. Int J Chron Obstruct Pulmon Dis. 2018;13:2351-60.

24. Frith P, Crockett A, Beilby J, Marshall D, Attewell R, Ratnanesan A, et al. Simplified COPD screening: validation of the PiKo- $6{ }^{\circledR}$ in primary care. Prim Care Respir J. 2011:20(2):190-8.

25. Nishimura K, Nakayasu K, Kobayashi A, Mitsuma S. Case identification of subjects with airflow limitations using the handheld spirometer " $\mathrm{Hi}$ -

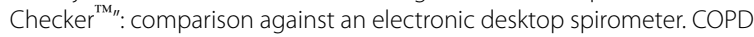
2011:8(6):450-5.

26. Rosa FW, Perez-Padilla R, Camelier A, Nascimento OA, Menezes AM, Jardim JR. Efficacy of the FEV1/FEV6 ratio compared to the FEV1/FVC ratio for the diagnosis of airway obstruction in subjects aged 40 years or over. Braz J Med Biol Res. 2007;40(12):1615-21.

27. Swanney MP, Jensen RL, Crichton DA, Beckert LE, Cardno LA, Crapo RO. FEV (6) is an acceptable surrogate for FVC in the spirometric diagnosis of airway obstruction and restriction. Am J Respir Crit Care Med. 2000;162(3 Pt 1):917-9.

28. Thorn J, Tilling B, Lisspers K, Jörgensen L, Stenling A, Stratelis G. Improved prediction of COPD in at-risk patients using lung function pre-screening in primary care: a real-life study and cost-effectiveness analysis. Prim Care Respir J. 2012;21(2):159-66.

29. Vandevoorde J, Verbanck S, Schuermans D, Kartounian J, Vincken W. FEV1/FEV 6 and FEV 6 as an alternative for FEV1/FVC and FVC in the spirometric detection of airway obstruction and restriction. Chest. 2005;127(5):1560-4

30. Miller MR, Crapo R, Hankinson J, Brusasco V, Burgos F, Casaburi R, et al. General considerations for lung function testing. Eur Respir J. 2005;26(1):153-61.

31. Miller MR, Hankinson J, Brusasco V, Burgos F, Casaburi R, Coates A, et al. Standardisation of spirometry. Eur Respir J. 2005;26(2):319-38.

32. Mortimer KM, Fallot A, Balmes JR, Tager IB. Evaluating the use of a portable spirometer in a study of pediatric asthma. Chest. 2003;123(6):1899-907.

33. Buist AS, McBurnie MA, Vollmer WM, Gillespie S, Burney P, Mannino DM, et al. International variation in the prevalence of COPD (the BOLD Study): a population-based prevalence study. Lancet. 2007;370(9589):741-50.

34. Giavarina D. Understanding bland Altman analysis. Biochem Med (Zagreb). 2015;25(2):141-51

35. Zaki R, Bulgiba A, Ismail R, Ismail NA. Statistical methods used to test for agreement of medical instruments measuring continuous variables in method comparison studies: a systematic review. PLoS ONE. 2012:7(5):e37908

36. Bland JM, Altman DG. Statistical methods for assessing agreement between two methods of clinical measurement. Lancet. 1986:1(8476):307-10.
37. Dirksen A, Madsen F, Pedersen OF, Vedel AM, Kok-Jensen A. Long-term performance of a hand held spirometer. Thorax. 1996;51(10):973-6.

38. Malmberg LP, Hedman J, Sovijärvi AR. Accuracy and repeatability of a pocket turbine spirometer: comparison with a rolling seal flow-volume spirometer. Clin Physiol. 1993;13(1):89-98.

39. Brouwer AF, Roorda RJ, Brand PL. Comparison between peak expiratory flow and FEV(1) measurements on a home spirometer and on a pneumotachograph in children with asthma. Pediatr Pulmonol. 2007;42(9):813-8.

40. Walker PP, Mitchell P, Diamantea F, Warburton CJ, Davies L. Effect of primary-care spirometry on the diagnosis and management of COPD. Eur Respir J. 2006;28(5):945-52.

41. Exarchos KP, Gogali A, Sioutkou A, Chronis C, Peristeri S, Kostikas K. Validation of the portable Bluetooth ${ }^{\circledR}$ Air Next spirometer in patients with different respiratory diseases. Respir Res. 2020;21(1):79.

42. Walters JA, Wood-Baker R, Walls J, Johns DP. Stability of the EasyOne ultrasonic spirometer for use in general practice. Respirology. 2006;11(3):306-10.

43. Schermer TR, Jacobs JE, Chavannes NH, Hartman J, Folgering HT, Bottema $\mathrm{BJ}$, et al. Validity of spirometric testing in a general practice population of patients with chronic obstructive pulmonary disease (COPD). Thorax. 2003;58(10):861-6.

44. Derom E, van Weel C, Liistro G, Buffels J, Schermer T, Lammers E, et al. Primary care spirometry. Eur Respir J. 2008;31(1):197-203.

\section{Publisher's Note}

Springer Nature remains neutral with regard to jurisdictional claims in published maps and institutional affiliations.

Ready to submit your research? Choose BMC and benefit from

- fast, convenient online submission

- thorough peer review by experienced researchers in your field

- rapid publication on acceptance

- support for research data, including large and complex data types

- gold Open Access which fosters wider collaboration and increased citations

- maximum visibility for your research: over $100 \mathrm{M}$ website views per year

At BMC, research is always in progress.

Learn more biomedcentral.com/submissions 